\title{
A INFLUÊNCIA DOS MITOS NA FAMILIA: UMA REFLEXÃO COM VISTAS A UM CUIDADO CONGRUENTE NO PROGRAMA SAÚDE DA FAMÍLIA
}

\section{THE INFLUENCE OF MYTHS ON FAMILY: A REFLECTION TOWARDS CONGRUENT CARE FOR THEY FAMILY HEALTH PROGRAM}

\section{LA INFLUENCIA DE LOS MITOS EN LA FAMILIA: UNA REFLEXIÓN ANHELANDO UN CUIDADO ADECUADO EN EL PROGRAMA DE LA SALUD DE LA FAMILIA}

Florence J.S. Munhoz ${ }^{1}$

Maria de Lourdes Centa ${ }^{2}$

Maria Helena Lenardt ${ }^{3}$

1 Enfermeira da Prefeitura Municipal de Curitiba. Mestranda do Programa de Pós-Graduação em Enfermagem da Universidade Federal do Paraná. Enfermeira. Doutora em Filosofia da Enfermagem. Professora Senior e Coordenadora do Grupo de Estudos Família Saúde e Desenvolvimento do Programa de Pós-Graduação em Enfermagem da Universidade Federal do Paraná.

3 Enfermeira. Doutora em Filosofia da Enfermagem pela UFSC. Professora Senior e Coordenadora do Grupo Multiprofissional da Pesquisa do Idoso do Programa de Pós-Graduação em Enfermagem da Universidade Federal do Paraná.

RESUMO: Este artigo é uma reflexão sobre a presença dos mitos e sua influência na vida dos homens. Conhecer os mitos é fundamental para compreender sua história, cultura, crenças e valores. Neste estudo abordamos a influência e o poder dos mitos nas famílias; enfoca-se sua importância e ação no comportamento de adolescentes, os quais, muitas vezes, são os atores da gravidez precoce. Aponta para a necessidade do enfermeiro conhecer e discutir os mitos familiares, pois isso ajuda a entender as relações familiares, suas expectativas e necessidades, o que possibilita o planejamento e implementação de ações eficazes e resolutivas à família.

PALAVRAS CHAVE: Enfermagem; Mito; Família; Programa Saúde da Família.

ABSTRACT: This is a reflection about the presence and influence of myths on one's life. Understanding myths is essential to one's understanding of his/her history, culture, beliefs and values. This study approaches myths influence and power on family; focusing its importance and action on adolescent's behavior that many times results in premature pregnancy. It indicates the nurse's necessity to know and to discuss the familiar myths. This can help to understand families relations and their necessity and expectance, that allows planning and take efficient actions towards the family.

KEY-WORDS: Nursing; Myth; Family; Family Health Program.

RESUMEN: Este artículo es una reflexión sobre los mitos presentes en la vida de los hombres y sus influencias. Conocer los mitos es fundamental para poder comprender su historia, cultura, credos y tradiciones. En este estudio abordamos la influencia y el poder de los mitos en las familias; muestra su importancia y la acción en el comportamiento de los jóvenes, los que muchas veces, son los actores de embarazos precoses. Señala la precisión que el enfermero tiene que tener de conocer y dialogar los mitos familiares, ya que esto lo ayudara a entender las relaciones familiares, expectativas y necesidades, lo que le permitirá proyectar y efectuar acciones eficientes y resolutivas para la familia.

PALABRAS CLAVES: Enfermería, Mito; Familia; Programa de Salud de la Família.

Recebido em: 01/03/2004

Aceito em: $\quad 30 / 04 / 2004$
Maria de Lourdes Centa

Rua Pará, 1235

80610-020 - Curitiba - PR

E-mail: mcenta@brturbo,com.br 


\section{INTRODUÇÃO}

A Enfermagem, por intermédio do Programa Saúde da Família (PSF), instituído pelo Governo Federal em 1994, foi colocada diante de um novo modelo de assistência que está centrado na família, o qual prioriza as ações de promoção, proteção e recuperação da saúde dos indivíduos e da família, entendida e percebida a partir do ambiente em que está inserida. Para esta prática de atendimento integral às famílias, há necessidade de maior compreensão do processo saúde-doença e de intervenções que vão além de práticas curativas. Isto faz com que os profissionais que atuam no PSF busquem conhecimentos e habilidades que atendam às novas demandas da assistência às famílias, que são consideradas como unidades de cuidado. Neste processo ocorre maior interação e proximidade dos profissionais de enfermagem com a intimidade das famílias, propiciando-Ihes conhecimento e entendimento a respeito de sua dinâmica, sentimentos, medos, expectativas, cultura, crenças, valores, papéis familiares, padrões de comunicação e o poder dos mitos nas famílias.

Considerando que todas as organizações familiares possuem seus mitos que agem silenciosos e influenciam diretamente no surgimento dos mitos individuais e ainda que a sua influência é percebida nas relações com as pessoas e com o mundo, na história das famílias e da sociedade, eis o que motivou a realização deste estudo. Compreendê-los ajudanos a perceber a força da imaginação dos homens e o poder do mito em suas vidas, no modo de viver, conviver e nas tomadas de decisões. Por conseguinte, acreditamos que a apreensão desse conhecimento por parte dos profissionais de enfermagem poderá contribuir no planejamento e implementação de uma assistência de qualidade, com compreensão mais aprofundada da dinâmica das relações, das necessidades sentidas e da realidade vivida pelos familiares. Para isso há a necessidade do estabelecimento de vínculos e laços de confiança entre profissional e família, para que juntos busquem o entendimento e a resolução dos problemas.
Desta forma, neste artigo pretendemos fazer uma reflexão a respeito da presença dos mitos e sua influência na vida dos homens, sua história, cultura, crenças e valores como influenciadores das relações intra e extrafamiliares.

\section{MITOS E FAMÍLIA}

Originária do grego, mythos é derivado de dois verbos: mytheyo- contar, narrar e mytheo- conversar, contar, anunciar, nomear, designar, o termo mito, com o passar do tempo, adquiriu diferentes significados. Para os gregos trata-se de um discurso pronunciado para ouvintes que recebem como verdadeira a narrativa porque confiam em quem narra ${ }^{1}$. Ele nasceu do desejo de entender o mundo e tem sua origem na vida comum e nas experiências de uma comunidade particular. Leva a marca de sua cultura, é sempre uma representação coletiva, transmitido através de várias gerações e relata uma explicação do mundo que não é objeto de discussão; ao contrario, ele une e canaliza as emoções coletivas, tranqüilizando o homem no mundo que o ameaça, e persiste como parte de sua tradição. É indispensável à vida social, na medida em que fixa modelos de realidade e de atividades humanas. "O mito não se justifica, não se contesta; portanto nem se presta à crítica ou à correção. É ilógico e irracional e não pode ser provado nem questionado"2.

No âmbito da religião, o Cristianismo condenou o mito ao inferno, como maléfico e ligado ao politeísmo. O iluminismo seguiu desprezando este conceito até o romantismo, que recuperou sua importância e, no século passado, as ciências da linguagem, a literatura, a antropologia e a psicanálise restituíram seu caráter fundante, sua riqueza de sentido, seu simbolismo; apesar disso ficou a velha idéia do mito associado à mentira ${ }^{3}$.

Para Jung os mitos nascem do inconsciente coletivo, uma camada subterrânea da psique comum à humanidade, na qual são armazenados todos os registros das experiências humanas desde os tempos mais remotos. Nesse inconsciente coletivo, 
os temas importantes para a humanidade são absorvidos pelo imaginário popular em forma de lendas, superstições, manifestações artísticas e rituais, que guiarão os povos durante certo período de seu amadurecimento psíquico ${ }^{4}$.

Para o filósofo Edgar Morin os mitos tomaram forma, consistência e realidade baseadas em fantasias formadas por nossos sonhos e imaginação. As idéias tomaram forma, consistência e realidade com base nos símbolos e nos pensamentos oriundos de nossa inteligência. Mitos e idéias deram-nos emoções e sentimentos como amor, raiva, êxtase, fúria. As sociedades domesticaram os indivíduos por meio de mitos e idéias; entretanto os indivíduos podem domesticar as idéias e, ao mesmo tempo, controlar a sociedade que os controla ${ }^{5}$.

Este autor define o ser humano como um ser plenamente biológico e cultural e vê a cultura como algo formado pelo complexo de normas, mitos, símbolos e imagens que penetram na intimidade do indivíduo, estruturando suas emoções e orientando suas ações, fazendo parte do seu cotidiano. Para ele a cultura acumula em si o que é conservado, transmitido e aprendido, possibilitando a aquisição de normas e princípios. O homem só se realiza plenamente por intermédio da cultura, pois ela é constituída pelo conjunto dos saberes, fazeres, regras, normas, proibições, estratégias, crenças, idéias, valores, ritos e mitos, transmitidos de geração a geração e se reproduzem em cada indivíduo e controlam a sociedade mantendo a complexidade psicológica e social. Afirma, ainda, que existe em cada cultura um capital específico de crenças, idéias, valores e mitos que unem uma comunidade singular a seus ancestrais através de suas tradições e de seus mortos ${ }^{5}$. O mito articula o mundo inconsciente com o consciente, o passado com o presente e está por trás dos rituais que compreendem todas as condutas repetitivas que têm por função reforçar o pólo mítico de um grupo, fazendo-o evidente. A vida em sociedade é repleta de rituais, desde a concepção até a morte. Assim, "o rito é a práxis do mito, é o mito em ação"2:63.
É uma realidade a presença e a influência dos mitos na vida dos homens e na historia de cada um; pois "mito e razão se complementam em nossas

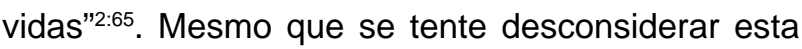
influência, verificamos sua força nas relações e interações familiares, pois o indivíduo nasce inserido em uma história familiar, de forma que cada vez que a história de vida de um membro da família é contada, nela estão embutidos modelos a serem seguidos ou rejeitados, os quais se vão enraizando em cada geração. É através dessa herança cultural que cada membro da família recebe uma série de missões e projeções dos pais, avós, família extensiva e da sociedade. Essa herança normalmente é transmitida de forma inconsciente e impercebível ${ }^{6}$.

O entendimento sobre a influência dos mitos na família, suscita uma compreensão antecipada de família e sua função na sociedade. Considerada o fundamento básico e universal das sociedades, a família é um grupo social, caracterizado pela residência comum, com cooperação econômica e reprodutiva, cuja estrutura e funcionamento podem variar, dependendo do meio a que pertença ${ }^{7}$.

A família representa um sistema dinâmico e historicamente seu conceito e sua organização vêm sofrendo constantes transformações, pois inicialmente era tida como fenômeno biológico de conservação e reprodução, transformando-se, no decorrer dos tempos, em fenômeno social, regulamentando suas bases conjugais de acordo com leis contratuais, normas religiosas e morais, que estabeleceram regras para as relações sexuais e a procriação de filhos ${ }^{7}$.

Nessa concepção surge a família nuclear ou elementar, considerada a base da estrutura social, pois nela se originam as relações primárias de parentesco. É formada por um homem, sua companheira e seus filhos que vivem juntos e compartilham ações, reações e decisões. Na base da formação do núcleo familiar está o casal que tem seus alicerces na fase de namoro, que é o momento da escolha do parceiro e, também, é quando se iniciam as primeiras negociações e padrões de relacionamento que podem dar origem a um novo 
núcleo familiar. Eles trazem consigo expectativas, crenças e valores a respeito do que é família e como esta se posiciona nas relações sociais ${ }^{7: 8}$.

Quando pensamos em família imediatamente nos reportamos a uma imagem de proteção, cuidado, educação e preservação de seus membros. Como agente educador, a família pode combinar duas funções especificas: socializadora na medida em que transmite a herança cultural (linguagem, mitos, ritos, usos, costumes, valores, crenças) e social quando proporciona a conquista de diferentes status, como o étnico, nacional, religioso, residencial, de classe, político e educacional ${ }^{7}$. Nessa dinâmica, a mulher possui papel importante de disseminadora da cultura através dos filhos; portanto é ela que os coloca em contato com o mundo, ensina-Ihes as diferenças básicas dos papéis sexuais, inicia sua socialização, mostra-lhes o sentido dos laços que ligam os seres humanos entre si e o de vida, introduzindo-os no sistema de valores da sociedade ${ }^{9}$.

A família compreende todo o sistema emocional de três ou mais gerações, sendo responsável pelo apoio emocional dos indivíduos e, também, pelos seus costumes relacionais ${ }^{8}$. Ela percorre o seu ciclo de vida como um todo orgânico, pois seus membros interagem, se articulam, se movimentam e se transformam de acordo com as situações vivenciadas, fazendo com que tenham de se adaptar às novas exigências e tarefas solicitadas pelo seu modo de viver ${ }^{10}$

No decorrer do tempo a família passa por estágios de desenvolvimento, previsíveis e importantes, que ocorrem como resultado das mudanças em sua organização, como o casamento, o nascimento dos filhos, o ingresso dos filhos na vida escolar, a adolescência, a saída dos jovens de casa ou seu casamento, a aposentadoria, a velhice e a morte, que caracterizam as etapas do ciclo vital familiar. Cada estágio é caracterizado por tarefas específicas de desenvolvimento e por crises relacionadas com a execução ou não das tarefas próprias de cada etapa do ciclo de vida familiar, principalmente por ocasião da transição de uma etapa para outra. $O$ estresse familiar se evidencia por ocasião do rompimento de uma etapa e o início de outra, onde a família se torna vulnerável ao surgimento de problemas e de doenças. Perceber estes momentos vividos pelas famílias ou reconhecer quando uma nova etapa vai instalar-se pode minimizar o seu estresse, pois toda a mudança requer de cada membro uma adaptação ao novo arranjo, com redefinição de papéis, espaços e divisão de tarefas ${ }^{8 ; 11}$.

O ser humano tem necessidade de se sentir incluído em um grupo e o instrumento natural para que isto ocorra é a família, a qual cumpre o seu papel de garantir a pertença e ao mesmo tempo promover a individualização do sujeito. Ela, portanto, é o primeiro sistema social em que o ser humano é inserido desde seu nascimento e onde cada um de seus membros passa por uma série de papéis de acordo com a idade, sexo e inter-relações, existindo uma interdependência, de forma que cada papel desempenhado altere e retro-alimente o sistema. A formação de papéis masculinos e femininos se dá a partir da educação recebida em casa, na escola e pelos meios de comunicação, em que a herança cultural, os mitos e crenças são fatores contribuintes para a sua formação dentro de cada contexto social.

Na união de duas pessoas ocorre o encontro de dois sistemas familiares diferentes, resultantes, por sua vez, de quatro outros, na intenção de criar um novo sistema familiar, passando a coexistir diferentes mitos pertencentes a cada família, pois as famílias de origem influenciam fortemente, na construção e configuração das novas famílias, as quais necessitam de tempo para se ajustar e para efetuar o encaixe mítico. É necessária, portanto, flexibilidade e habilidade nas negociações dos mitos herdados por cada um dos parceiros, para não gerar conflitos na formação e condução da nova família, principalmente por causa das expectativas que se criam em torno de cada um dos parceiros e do casal. No casamento, os acordos são considerados verdadeiros rituais que servem tanto para a manutenção dos mitos, como para a passagem do casal pelos períodos de encaixe e ajustes míticos ${ }^{10}$. 
Os mitos familiares são histórias que se perpetuam na família e cumprem importante função, pois são eles que dão a cada família certa identidade ${ }^{10}$. Eles são transmitidos através do inconsciente, de diversas formas, sendo, muitas vezes, comunicados de forma sutil e não verbal, o que faz com que as pessoas nem se dêem conta de sua existência, importância e ação ${ }^{6}$.

O mito familiar é um sistema de crenças integradas e compartilhadas por todos os membros da família a respeito de seus papéis mútuos e a natureza de sua relação, fazendo com que a força do meio familiar esteja sempre viva e presente em cada um de seus membros. Estas crenças constituem a personalidade da família; portanto não são questionadas, pois são elementos de união e fator de coesão para os que crêem em suas verdades ${ }^{12}$.

A família possui diversos mitos; dentre eles temos: o mito da união que favorece o pertencimento e a manutenção dos padrões afetivos em que casar e viver feliz para sempre faz parte da concepção de família associada à idéia de refúgio, proteção e amor eterno; o mito da propriedade que está vinculado à preservação do patrimônio da família; o mito da religião que aparece comumente norteado pela prática de determinada religião por todos e que têm significados e conotações especiais; o mito da conquista e do sucesso que determinam maneiras de conquistar bens que proporcionam a seus membros status, fazendo-os sobressair em seu meio social; o mito da autoridade em que se estabelece uma hierarquia de poder em que seus membros exercem determinadas funções que asseguram sua autoridade; e o mito do poder encontrado nas famílias em que há abuso da autoridade, geralmente com histórias de patriarcado e autoritarismo 10:56-58.

Com a formação da nova família pressupõe-se a vinda dos filhos quando então cada grupo familiar introduz valores e expectativas sobre como o filho deve ser, como deve comportar-se e elabora sonhos sobre a vida futura da criança. Neste processo e no decorrer do tempo começam as profecias, como: ele será um grande médico, como o avô; os mandatos, como: somos uma família de médicos, esperamos que ele siga a mesma profissão; as comparações, ele não é comportado como o irmão; as lealdades, meus pais não gostavam de estudar, acho que também não preciso estudar muito; ou os segredos, omitem ao filho que é adotivo. Todas estas expectativas podem marcar profundamente 0 desenvolvimento futuro da criança impondo-lhe tarefas que estão em desacordo com suas capacidades, aptidões ou mesmo desejos, pois suas escolhas vão responder às expectativas individuais e familiares, fortemente determinadas e construídas pelas forças míticas intergeracionais ${ }^{10}$. Os filhos que rompem e frustram as expectativas construídas pelos pais representam a perda de sonhos e esperanças, o que os obriga a lidarem com seus mitos, valores e com suas limitações ${ }^{13}$. É nos momentos difíceis, em que a estrutura da família fica exposta e tornam-se visíveis suas normas e condutas, como também a sua força de sustentação, que se tornam visíveis seus mitos e a sua força. Neste processo existem vários fatores que fazem parte da vida familiar, porém não são expressos através da comunicação verbal, mas influenciam seu modo de viver e podem ser responsáveis pela criação de um ambiente estressante para todos os seus membros. Dentre eles, encontramos alguns mitos familiares, os quais podem ser nocivos e desorganizadores da estrutura harmônica da família, pois possibilitam condições para aumentar o estresse familiar, provocando ansiedade, rupturas, coalizões, distanciamentos físicos, condutas depressivas, drogadição, entre outras ${ }^{10}$.

"Geralmente as famílias repetem modelos e padrões de seus antepassados; estes podem gerar estresses que se vão acumulado de geração a geração, podendo produzir conflitos e dificuldades no relacionamento familiar, os quais se podem perpetuar no tempo. Dentre eles estão os casos de violência doméstica, drogadição e depressão, a gravidez na adolescência e a exposição freqüente a fatores de risco de vida"10:203. 
Ainda hoje, a formação de papéis, que devem ser exercidos pelos indivíduos, está fundamentada numa sociedade patriarcal, onde mitos sociais e familiares têm influenciado o relacionamento e comportamento das pessoas. Dentre eles observase o mito do homem-pai, tido como provedor, trabalhador, disciplinador, racional, dono do poder e independente; e o da mulher, como frágil, emotiva, sensível e dependente, os quais fazem parte do processo de socialização das crianças, pois se observa que para as meninas são destinadas e ensejadas brincadeiras com bonecas, fogões, panelinhas, contos de fada, príncipes encantados, enquanto os meninos são premiados com pescaria, futebol, brinquedos eletrônicos e jogos que despertam o raciocínio. A sociedade ainda cobra dos jovens o namoro, o casamento, pois tudo deve seguir o ritual preestabelecido para se constituir família e procriar, ou seja, para assumirem o papel de pai-mãe ${ }^{14}$.

A adolescência, como uma das etapas do ciclo vital familiar, comporta especificidades características e caracterizadoras, como período marcante na vida dos indivíduos e de suas famílias; além das modificações biopsicosociais, a sexualidade adquire dimensão especial através do aparecimento da capacidade reprodutiva. Concomitantemente, há a reestruturação do psiquismo, incorporação de novos valores éticos e morais da personalidade e novos comportamentos e atitudes em face da estrutura de padrões sociais e sexuais, fortemente influenciados pelas relações de gênero, estabelecidos social e culturalmente $^{15}$. Nesta etapa de vida, os jovens sentem necessidade de tornarem-se independentes dos pais e de construírem sua própria identidade, pois se desfaz a fantasia de pais onipotentes e eles passam a questionar e contrariar o estilo e os mitos familiares e os princípios morais que já não se enquadram na forma e à função da família atual. Devido a isso os pais se sentem afetados e envolvidos pela problemática do adolescente, à medida que reavivem em suas mentes a sua própria adolescência e a maneira como lidaram com questões como sexo, autonomia, escolha da profissão e do parceiro, entre outras questões importantes de sua vida. Portanto, quando existem problemas familiares sérios, estes se referem complementarmente tanto aos adolescentes quanto às suas famílias, os quais foram sendo construído ao longo do tempo, através de interações, ações e reações baseadas na herança cultural, que acompanha as famílias ao longo de sua história ${ }^{10}$.

Muitas vezes, devido a que os pais consideram os filhos como sua propriedade, estes reagem contra suas posições autoritárias, gerando conflitos nas relações e dificultando a individualização do adolescente. Nesta fase, as regras da família e seus mitos são desafiados e são testados seus limites, havendo necessidade de diálogo, flexibilização entre os envolvidos e manejo dos conflitos nas relações através do estabelecimento de limites, parcerias e responsabilidades, possibilitando a autonomia do adolescente $^{11}$

Deve-se observar também que nesta fase de incorporação de novos valores éticos, morais, de comportamentos e atitudes em face da estrutura de padrões sociais, sexuais e de formação de papéis masculinos e femininos, além dos mitos e crenças presentes nas sociedades, os adolescentes podem deixar-se influenciar por mitos e crenças equivocados, como, por exemplo: pensar que a gravidez é uma manifestação de feminilidade; que a mulher deve entregar-se ao homem para satisfazer o seu desejo ou como prova de amor; que a mulher que vivencia o sexo deve amar o seu parceiro; que o homem está sempre querendo e pronto para o sexo; que um homem não pode dizer não para o sexo. Portanto conhecer o padrão relacional dos adolescentes, suas crenças e mitos em relação aos seus papéis e do parceiro pode contribuir para se entender a gravidez na adolescência, a qual, atualmente, é considerada pelos serviços de saúde, como um problema.

Uma gravidez na adolescência provoca alterações ainda maiores na transformação que já vem ocorrendo na vida do adolescente, ou seja, implicam duplo esforço de adaptação interna que converge em um único momento: estar grávida e ser 
adolescente. A gravidez na adolescência geralmente cria dificuldade na relação com os pais por quebrar suas expectativas, levando-os ao desapontamento, provocando culpas e brigas. Ela também leva o adolescente a sentir receio das alterações que possam ocorrer no relacionamento com o parceiro e com o seu grupo de amigos. Estas ocorrências podem criar dificuldade na relação consigo mesmo, pois necessita integrar a gravidez e a expectativa da maternidade/paternidade aos seus projetos de vida. A imaturidade biopsicológica do adolescente e a pouca noção sobre o significado da gravidez e da maternidade/paternidade são alguns dos problemas decorrentes deste processo, pois a gravidez não os transforma em adultos de uma hora para a outra.

Portanto, quando os filhos chegam na adolescência, aumentam as possibilidades dos conflitos familiares e como conseqüência o aparecimento de doenças. Para ajudá-los a enfrentarem, de forma mais harmoniosa, esta fase, requer-se que a enfermagem conheça e compreenda seus mitos, ritos e valores familiares e sociais e o processo de ser/estar adolescente e o que isto representa tanto no contexto familiar como social.

\section{CONSIDERAÇÕES FINAIS}

Os mitos fazem parte da vida do homem, são transmitidos através de várias gerações e são indispensáveis na vida social, por fixarem modelos e ações humanas, construindo a realidade vivida pelo grupo social. Eles agem silenciosos e influenciam nossas relações com as pessoas e com o mundo que nos cerca; portanto conhecê-los ajuda-nos a compreender nossa história, nossa cultura, crenças e valores, pois mito e razão se complementam.

Os mitos culturais influenciam a formação dos mitos familiares, que influenciam diretamente os mitos individuais, interferindo na formação e conduta das pessoas. Neste processo a família, considerada o fundamento básico e universal da sociedade, que tem como funções a proteção, cuidado, educação e preservação de seus membros, sofre a influência de uma história familiar que compreende várias gerações, e recebe uma série de missões e projeções. $\mathrm{Na}$ base do núcleo familiar está o casal que dá início a esta formação e trazem expectativas, crenças, valores, ritos e mitos, que precisam ser compartilhados e organizados, através do encaixe e ajustes necessários, na busca de consenso e da diferenciação da família de origem, a fim de construir o relacionamento e obter uma convivência equilibrada e madura emocionalmente.

Numa linha do tempo, a família caminha atravessando determinados momentos em seu ciclo de vida, e passa por etapas características como o casamento, o nascimento dos filhos, o ingresso dos filhos na vida escolar, a adolescência, a saída dos jovens de casa ou seu casamento, a aposentadoria e a morte. Evidências apontam que o estresse familiar costuma ocorrer nos pontos de transição do ciclo de vida, podendo levar a família a passar por períodos de disfunções, conflitos e crises, provocando desgastes e consumindo boa parte da energia familiar; pode levá-los a adoecer e a buscarem a reorganização ou reconstrução de seus mitos.

A família tem como papel garantir a pertença e ao mesmo tempo promover a individualização dos filhos, mas Ihes impõem desde o nascimento, mesmo sem o saber, expectativas, valores e sonhos sobre como devem ser, e se comportar tanto no seio familiar como no mundo em que vivem. Isto pode marcar profundamente seu desenvolvimento, impondo-Ihes tarefas não condizentes com suas capacidades, aptidões ou desejos. $\mathrm{Na}$ adolescência, os filhos buscam a separação dos pais, pelo menos em parte, para que possa elaborar sua própria identidade; dependendo de como isto é compreendido pelos pais, pode acontecer de forma harmoniosa ou conflitiva.

Os mitos familiares dão a cada família certa identidade, pois existem vários mitos em uma família e na formação de cada nova família há a influência dos mitos da família de origem que precisam ser negociados e necessitam de tempo para que possam ajustar-se e efetuar o encaixe mítico. Assim os mitos familiares tanto podem ser nocivos, aumentando os 
estresses familiares, como benéficos, estreitando a relação entre os membros da família. Dessa maneira, o contexto familiar propende a influenciar grandemente o comportamento de seus componentes, tanto positiva como negativamente.

Para os Enfermeiros que prestam cuidados às famílias conhecer os mitos familiares e relacioná-los às etapas do ciclo de vida familiar poderá ajudá-los na compreensão da vida em família, levando-os a refletir sobre as etapas vividas e a ponderar a influência dos seus mitos nas suas relações, ajudando-os a reverem suas posições e conflitos, abrindo espaço para as negociações e entendimentos: muitas doenças têm suas origens em problemas familiares mal resolvidos. Assim como as doenças podem afetar, de alguma maneira, as interações familiares, estas também podem provocar doenças, porque mente, corpo e espírito funcionam como um todo. A aquisição de conhecimentos e informações, pelos enfermeiros sobre o viver em família leva-os ao diagnóstico e à compreensão das inter-relações familiares, proporcionando-Ihes melhores condições para lidar com seus problemas e necessidades e não apenas focando-os em seus indicadores físicos.

Conhecer e compreender os mitos familiares e sua influência sobre o desenvolvimento de comportamentos de seus membros pode tornar-se ferramenta importante no planejamento das ações dos profissionais de saúde principalmente das equipes de PSF. Estes que vivem em seu cotidiano o processo de assistir, cuidar de famílias possibilitalhes maior proximidade com a dinâmica de vida familiar e por vezes são solicitados a intervir em situações de conflito ou crises de relacionamento estabelecido entre seus membros. Conhecer seu modo de viver, seus mitos, ritos e valores poderá torná-los mais seguro para agir, favorecendo a solução do problema e atendendo às necessidades sentidas pelos familiares. Este conhecimento auxilia 0 enfermeiro a planejar e implementar ações que minimizam a problemática causada pela gravidez na adolescência, vivida pelas famílias. Portanto acreditamos que conhecer a família, através de uma interação eficiente, levará o profissional que atua no PSF não apenas a detectar seus problemas, mas também compreender seu modo de ser e viver em sociedade.

\section{REFERÊNCIAS}

1 Chaui M. Convite à filosofia.12. ed. São Paulo: Ática; 2001.

2 Aranha MLA, Martins MHP. Temas de filosofia. São Paulo: Moderna; 2002.

3 Botticelli S. O mito faz a história. www.livre pensarpsi.hpg.ig.com.br. Acesso em 10/07/04

4 Jung $C G$.

5 Morin E, 1921. Os sete saberes necessários à educação do futuro. São Paulo: Cortez; Brasília, DF: UNESCO; 2000.

6 Rivera CV. Los mitos en la terapía de familia. In: www.campogrupal.com/mitos. Acesso em 08/05/05.

7 Marconi MA, Presotto ZMN. Antropologia: uma introdução. 5. ed. São Paulo: Atlas; 2001.

8 Carter B, Mcgoldrick M. As mudanças no ciclo de vida familiar: uma estrutura para a terapia familiar, Porto Alegre: Artes Médicas; 1995.

9 Kitzinger S. Mães: um estudo antropológico da maternidade. Lisboa: Presença; 1978.

10 Krom M. Família e Mitos: Prevenção e terapia, resgatando histórias. São Paulo: Summus; 2000.

11 Oliveira E, et al. Ferramenta de avaliação para situações indefinidas e manobras preventivas em saúde da família - Ciclo de vida das famílias. Rev Méd Paraná, 1999; 57(1/2):22-7.

12 Ferreira AJ. "Mitos familiares" in interacción familiar. Org. Carlos Sluzki. Buenos Aires: Tiempo Contemporâneo; 1974.

13 Polity E. Dificuldade de aprendizagem e família: construindo novas narrativas. São Paulo: Editora Vetor; 2001.

14 Centa ML. Do natural ao artificial a trajetória de um casal infértil. Curitiba: Ed. do autor; 2001.

15 Ministério da Saúde (BR). Política Nacional de Atenção Integral à Saúde da Mulher: Princípios e Diretrizes. Secretaria de Atenção à Saúde, Departamento de Ações Programáticas Estratégicas. Brasília; 2004. 